10-1-2009

\title{
Interpretation of Single-Beam Acoustic Backscatter Using Lidar-Derived Topographic Complexity and Benthic Habitat Classifications in a Coral Reef Environment
}

\section{Greg Foster}

Nova Southeastern University

Brian K. Walker

Nova Southeastern University, walkerb@nova.edu

Bernhard Riegl

Nova Southeastern University, rieglb@nova.edu

Find out more information about Nova Southeastern University and the Halmos College of Natural Sciences and Oceanography.

Follow this and additional works at: https://nsuworks.nova.edu/occ_facarticles

Part of the Marine Biology Commons, and the Oceanography and Atmospheric Sciences and Meteorology Commons

\section{NSUWorks Citation}

Greg Foster, Brian K. Walker, and Bernhard Riegl. 2009. Interpretation of Single-Beam Acoustic Backscatter Using Lidar-Derived Topographic Complexity and Benthic Habitat Classifications in a Coral Reef Environment .Journal of Coastal Research, (Special Issue 53) : $16-26$. https://nsuworks.nova.edu/occ_facarticles/135. 


\begin{tabular}{|c|c|c|c|c|c|}
\hline Journal of Coastal Research & SI & 53 & $16-26$ & West Palm Beach, Florida \\
\hline
\end{tabular}

\title{
Interpretation of Single-Beam Acoustic Backscatter Using Lidar-Derived Topographic Complexity and Benthic Habitat Classifications in a Coral Reef Environment
}

\author{
Greg Foster*, Brian K. Walker, and Bernhard M. Riegl
}

National Coral Reef Institute

Nova Southeastern University Oceanographic Center

8000 N. Ocean Drive, Dania FL 33004, USA

*fjohn@nova.edu

\begin{abstract}
Foster, G.; Walker, B.K., and Riegl, B.M., 2009. Interpretation of single-beam acoustic backscatter using lidar-derived topographic complexity and benthic habitat classification in a coral reef environment. Journal of Coastal Research, SI(53), 16-26.

Producing thematic coral reef benthic habitat maps from single-beam acoustic backscatter has been hindered by uncertainties in interpreting the acoustic energy parameters E1 (tail of $1^{\text {st }} \mathrm{echo}$ ) and E2 (complete $2^{\text {nd }}$ echo), typically limiting such maps to sediment classification schemes. In this study, acoustic interpretation was guided by high-resolution lidar (LIght Detection And Ranging) bathymetry. Each acoustic record, acquired from a BioSonics DT-X echosounder and multiplexed 38 and $418 \mathrm{kHz}$ transducers, was paired with a spatially-coincident value of a lidar-derived proxy for topographic complexity, reef-volume (RV), and its membership to one of eight benthic habitat classes, delineated from lidar imagery, ground-truthing, and characterization of epibenthic biota. The discriminatory capabilities of the 38 and $418 \mathrm{kHz}$ signals were generally similar. Individually, the E1 and E2 of both frequencies differentiated between levels of RV and most habitat classes, but could not unambiguously delineate habitats. Plotted in E1:E2 Cartesian space, both frequencies formed two main groupings: uncolonized sand habitats and colonized reefal habitats. E1 and E2 were significantly correlated at both frequencies: positively over sand habitats and negatively over reefal habitats, where the scattering influence of epibenthic biota strengthened the E1:E2 interdependence. However, sufficient independence existed between E1 and E2 to clearly delineate habitats using the multi-echo E1:E2 bottom ratio method. The point-by-point calibration provided by the lidar data was essential for resolving the uncertainties surrounding the factors informing the acoustic parameters in a large, survey-scale dataset. The findings of this study indicate that properly interpreted single-beam acoustic data can be used to thematically categorize coral reef benthic habitats.
\end{abstract}

ADDITIONAL INDEX WORDS: AGDS, acoustic ground discrimination, benthic survers, E1, E2, echo, habitat mapping, coral reef, South Florida

\section{INTRODUCTION}

Considerable effort has been spent on defining the operational parameters within which single-beam Acoustic Ground Discrimination Systems (AGDS) can be used for benthic classification. Their popularity is due to their relatively low cost, ease of deployment, rapid assessment potential, and comparative insensitivity to water column effects. Hamilton (2001) and McCauley and Siwabessy (2006) provide comprehensive reviews of commercially available AGDS, their underlying physics, principles of operation, and case studies. A typical approach to acoustic seabed classification has been to use sediment classification as a surrogate for benthic habitat, using either the first-echo shape analysis of QTC View, or a multi-echo method as with RoxAnn, ECHOplus, or BioSonics echosounders (Anderson, Gregory, and Collins, 2002; Ellingsen, Gray, and Bjornbom, 2002; Freitas, Rodrigues, and Quintino, 2003; Freitas et al., 2003; Freitas et al., 2005; Freitas et al., 2006; Greenstreet et al., 1997; Hamilton, Mulhearn, and Poeckert, 1999; Riegl et al., 2007). There is an obvious need for thematic mapping of shallow-water coral reef habitats, and while progress has been made with single-beam AGDS, technical challenges to

DOI: $10.2112 / S I 53-003.1$ thematic classification remain (Foster-Smith and Sotheran, 2003; Halley and Bruce, 2007; Moyer et al., 2005; Riegl and Purkis, 2005; White et al., 2003).

A major impediment to the classification of topographically complex coral reef habitats is an incomplete understanding of how physical seabed factors are interpreted by the acoustic parameters E1 (time integral of the squared amplitude of the tail of the $1^{\text {st }}$ echo waveform) and E2 (complete $2^{\text {nd }}$ echo). E1 and E2 are often referred to as measures of roughness and hardness, but in reality they are acoustic indices with unknown relationships to seabed conditions (Hamilton, Mulhearn, and Poeckert, 1999). The E1:E2 bottom ratio is commonly used to interpret single-beam AGDS output, whereby ground-truthed E1:E2 data-pairs are plotted onto a Cartesian XY plane and user-defined boxes are drawn around clusters of points. Ideally, these clusters are well separated in E1:E2 space and can be related to distinct habitats. In practice, distinct clusters are not typically found when the number of categories is expanded to encompass the numerous habitats encountered on a coral reef ecosystem (Foster-Smith and Sotheran, 2003). Several physical attributes associated with coral reefs add to the list of uncertainties, e.g., substratum patchiness, rocky outcrops, steep slopes, and spatial and temporal variability of epibenthic biota. Physical properties of the seabed can rarely be satisfactorily related to values of E1 and E2 due to the time and expense constraints of 
conventional ground-truthing methods such as video drop cameras or scuba divers.

This paper uses a lidar survey as the backdrop for a point-bypoint interpretation of acoustic data acquired from a single-beam, multiple-frequency ( 38 and $418 \mathrm{kHz}$ ) AGDS survey. The study area encompasses $2.3 \mathrm{~km}^{2}$ of sand, hardbottom, and reefal habitats in the waters offshore of Palm Beach County, FL. The appropriateness of lidar reef-volume (RV) as a proxy for topographic complexity is first established by confirming that it rationally orders and differentiates between benthic habitats. The relationships between RV:E1 and $\mathrm{RV}: \mathrm{E} 2$ are then examined to reveal the acoustic interpretation of the seascape (irrespective of biotic cover, owing to an object-detection algorithm used in lidar post-processing). The acoustic interpretation of seascape plus biota is similarly revealed by the relationships between E1 and E2 and benthic habitat class. Collateral outputs include: (i) a clearer picture of which physical seabed factors inform an AGDS survey of coral reef habitats, and (ii) insights toward the discriminatory capabilities of two frequencies at the extremes of those typically employed for AGDS.

\section{METHODS}

\section{Lidar Survey}

In November 2002, a laser bathymetric survey was conducted by Tenix LADS Corporation of Australia, using the Laser Airborne Depth Sounder (LADS) system with a sounding rate of $900 \mathrm{~Hz}$ (3.24 million soundings per hour), a positioning accuracy of $95 \%$ at $5 \mathrm{~m}$ circular error probable, a horizontal sounding density of 4 $\mathrm{x} 4 \mathrm{~m}$, a swath width of $240 \mathrm{~m}$, and an area coverage of $64 \mathrm{~km}^{2} / \mathrm{hr}$. The survey encompassed all of Palm Beach County from the shore eastward to depths of $40 \mathrm{~m}$.

\section{Benthic Habitat Mapping}

Benthic habitats were identified and outlined by visual interpretation of the lidar image in ArcGIS 9.3 at a scale of 1:6000 using a one acre minimum mapping unit. The lidar data were gridded by triangulation with linear interpolation and sun-shaded at a $45^{\circ}$ angle and azimuth. This final image was used as the foundation for benthic habitat mapping, along with video groundtruthing of the substrate and characterization of the epibenthic community. Accuracy assessment by confusion matrix yielded a total map accuracy of $89.2 \%$. Further details of the mapping methodology can be found in Walker, Riegl, and Dodge (2008). Brief descriptions of the benthic habitats present within the acoustic survey extent, derived from Kendall et al. (2001), include:

Sand: Coarse, unconsolidated sediment typically found in areas exposed to currents or wave energy.

Deep sand: Sand habitat beyond the $25 \mathrm{~m}$ contour, with variable rubble content.

Sand over hardbottom: A thin veneer of sand habitat covering uncolonized hardbottom, apparent as an undulating, stepped, or otherwise uneven surface beneath the sand.

Colonized pavement: Flat, low-relief, solid carbonate rock with coverage of macroalgae, hard coral, gorgonians, and other sessile invertebrates that are dense enough to partially obscure the underlying carbonate rock.

Ridge-Deep: Linear, shore-parallel, low-relief features that appear to be submerged, cemented beach dunes. Characterized as hardground with variable and shifting sand cover. Benthic community structure is similar to that of colonized pavement, but less abundant overall.

Aggregated patch reef: Clustered patch reefs that individually are too small or are too close together to map separately, interspersed in sand.

Linear reef-outer: Linear coral formations oriented parallel to shore; forms the reef crest of the outer reef tract of Broward and Palm Beach Counties.

Spur and groove: Alternating sand and coral formations oriented perpendicular to shore, occurring in the fore reef or bank/shelf escarpment of the outer reef tract.

\section{Acoustic Survey}

The data used in this paper was taken from a larger acoustic survey that covered all of Palm Beach County, FL from depths of 3-35 m. The study area was surveyed on June 27-28, 2006 using a BioSonics DT-X echosounder and two multiplexed, single-beam digital transducers with full-beam widths of $10^{\circ}(38 \mathrm{kHz})$ and $6.4^{\circ}$ $(418 \mathrm{kHz})$, operated at $5-\mathrm{Hz}$ sampling frequency and $0.4 \mathrm{~ms}$ pulse duration. Survey lines were run parallel to shore at $75 \mathrm{~m}$ spacing, from the nearshore sand flats $($ depth $=11 \mathrm{~m})$ to the seaward slope of the outer reef terrace (depth $=35 \mathrm{~m}$ ), encompassing an area of $2.3 \mathrm{~km}^{2}$ (Figure 1). Global positioning data were collected with a Trimble Ag132 dGPS, differentially corrected against U.S. Coast Guard beacons and WAAS signal to achieve positioning accuracies less than $0.9 \mathrm{~m}$ horizontal dilution of precision. To avoid turbulenceinduced signal contamination, evident as a rolling oscillation on the real-time BioSonics Visual Acquisition display, vessel speed was adjusted to maintain net speed (vessel plus drift) at approximately 4.5 knots.

\section{Data Processing}

The 38 and $418 \mathrm{kHz}$ survey data were processed using BioSonics Visual Bottom Typer (VBT) seabed classification software (v1.10.6.3) to obtain values of E1 and E2. Log-transformed values of $\mathrm{E} 1$ and E2 were passed through 2.5 and 97.5 percentile filters and then empirically normalized to the median survey depth. Empirical normalization was necessary because the current version of VBT does not normalize echo length to a reference depth, a prerequisite for proper valuation of E1 and E2 values using fixed sampling windows (Dommisse et al., 2005). Depth-normalization models were constructed using data collected from and adjacent to the study area, constrained to the relatively featureless sand and deep sand habitats, where it could be assumed that depth was the primary factor affecting the shape of echo returns. Third-order polynomials were fit to plots of log-transformed energy versus depth for each of the four acoustic parameters (Figure 2). Correction factors were calculated as the ratio of model-predicted acoustic energy at the actual depth divided by model-predicted acoustic energy at the median depth.

A value of reef-volume (RV) was calculated for each acoustic record by creating a $7.62 \mathrm{~m}(25 \mathrm{ft})$ diameter circular polygon around each acoustic data point location (Figure 3 ). The volume between a lidar-derived triangulated irregular network surface and the maximum depth within each polygon was calculated in ArcView 3.3 using the "Surface Tools (v.1.6)" extension (Jenness, 2006). 


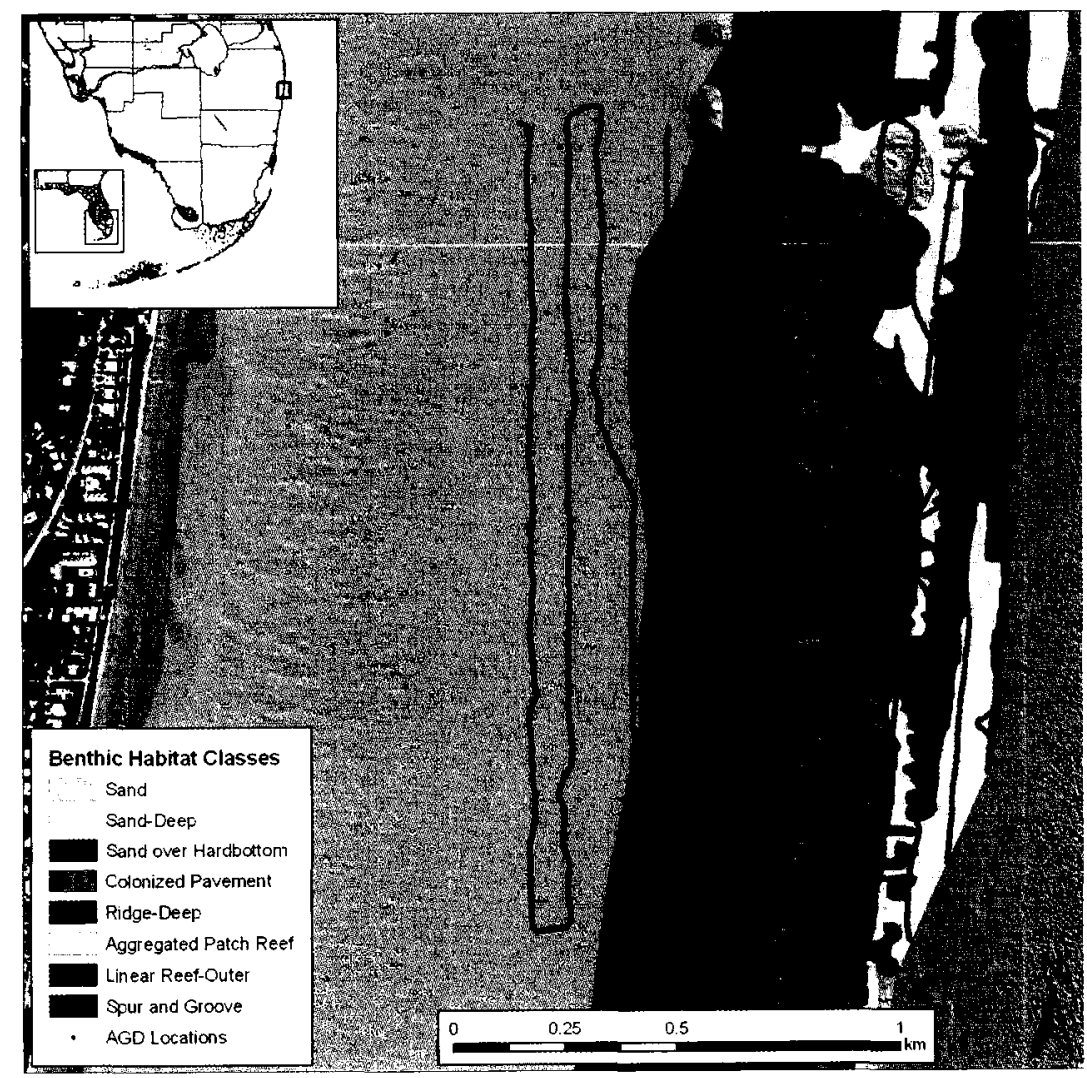

Figure 1. Acoustic survey track-lines ( $75 \mathrm{~m}$ spacing) overlaying lidar bathymetry. Color shading denotes benthic habitat classes delineated from lidar imagery, video ground-truthing of the substrate, and characterization of the epibenthic community.

\section{E1:E2 Bottom Ratio Method}

Acoustic habitat classification was performed using the E1:E2 bottom ratio method developed by Orlowski (1984) and refined by Chivers, Emerson, and Burns (1990). Depth-normalized and log-transformed E1:E2 data-pairs were passed though 20 and 80 percentile filters and plotted onto a Cartesian XY plane. The task of drawing boxes around clusters of data, i.e., habitat classes, was facilitated by the additional $20 / 80$ percentile filters, which preferentially removed co-mingled data points. Error matrices were produced from comparisons of acoustic versus lidar habitat classifications for records falling within the boxes, with and without the 20/80 percentile filters. Classification accuracy was evaluated by the overall accuracy, Po, and the Tau coefficient for equal probability of group membership ( $\mathrm{Te}$ ), which measures the improvement of a classification scheme over random assignment of records to habitat classes (Ma and Redmond, 1995).

\section{EcoSAV Canopy Height}

Colonies of erect gorgonians, locally abundant and variable within and between the reefal and hardbottom habitats of Palm Beach County, FL, are the most prominent biotic features. Rationalizing the acoustic-ordering of benthic habitats necessitated quantifying the abundance and distribution of gorgonian colonies. The $418 \mathrm{kHz}$ acoustic data was processed with BioSonics EcoSAV (v1.0) software, which predicts areal cover and canopy height of submerged aquatic vegetation (SAV) based on a series of pattern-recognition algorithms that examine plant features between the near-field and trailing edge of the first echo (Sabol et al., 2002). Though EcoSAV was designed to operate at a $0.1 \mathrm{~ms}$ pulse duration, it was possible to tune the user-defined settings to detect erect gorgonian colonies at the $0.4 \mathrm{~ms}$ pulse duration used in this study. The most critical settings were the plant height detection threshold and the bottom detection threshold, which were set to 29 and $47 \mathrm{~cm}$, respectively, to force the EcoSAV algorithms to predict near-complete areal coverage. The resultant plant canopy height estimates (adjusted to achieve zero height for sand habitat) were used as a proxy for gorgonian abundance.

\section{Statistical Analysis}

Post-hoc Tukey's honest significant difference (Tukey HSD) testing with modification to control for sample size (Kramer, 1956) was used to test the discriminatory capability of (i) RV to resolve benthic habitat class, (ii) acoustic energy parameters to resolve RV, and (iii) acoustic energy parameters to resolve benthic habitat class. The Kolmogorov-Smirnov statistic was used to test assumptions of normality of E1 and E2 data. The stability of E1 and E2 values over varying topographies was evaluated by coefficients of variation $(\sigma / \mu$ -100) calculated for each of the four acoustic parameters at the seven 

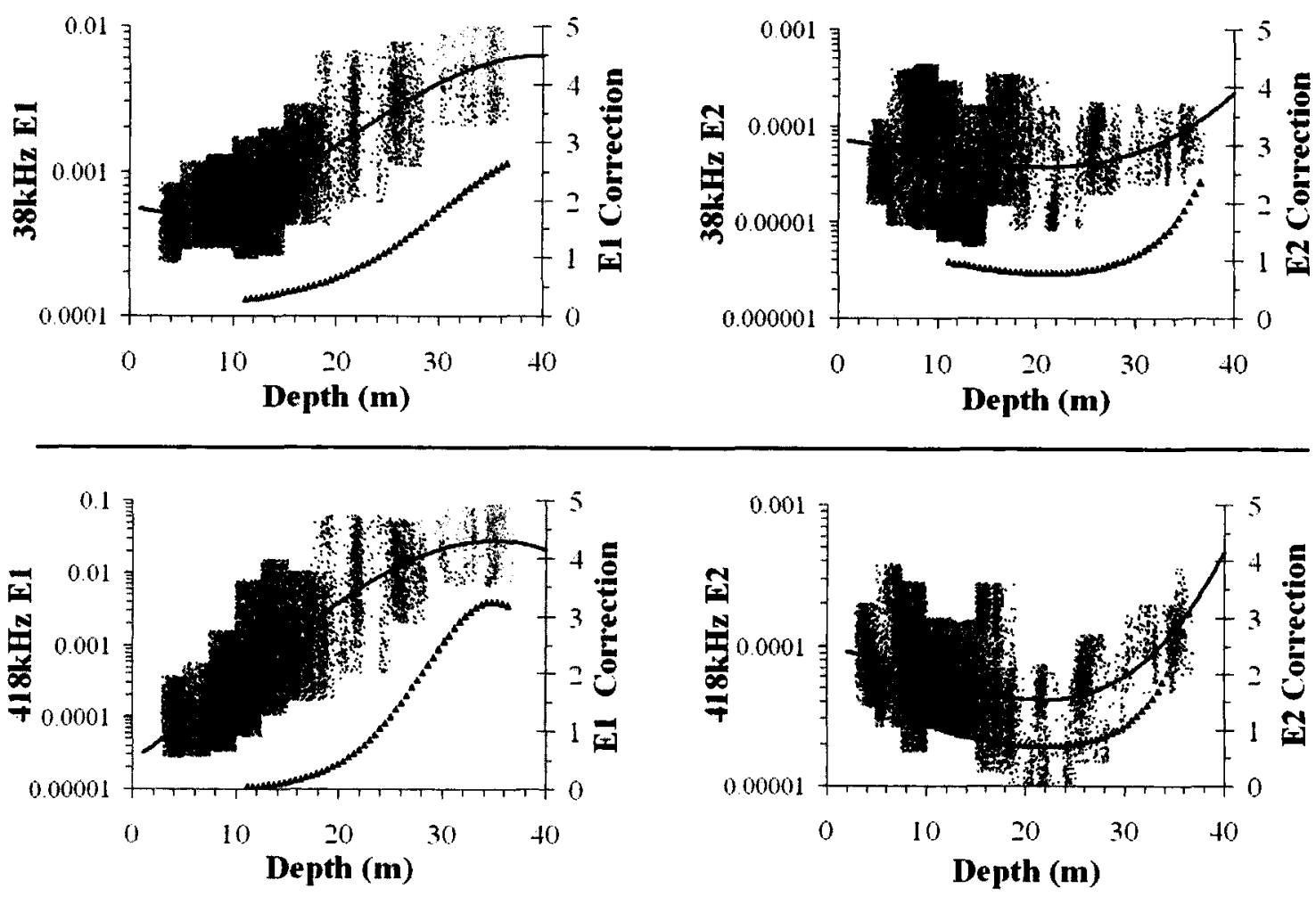

Figure 2. Normalization of acoustic energy parameters to median survey depth, using data collected over sand and deep sand habitats within and adjacent to the survey area. (Solid Line) Third-order polynomial fit to data. ( $\boldsymbol{\Delta}$ ) Correction factors derived from polynomial.

arbitrarily-selected levels of RV. The 95 percent confidence interval of the classification accuracy coefficient $(\mathrm{Te})$ was calculated as per $\mathrm{Ma}$ and Redmond (1995). The interdependence of the E1 and E2 parameters was quantified by the correlation coefficient ( $r$, using the 20-80 percentile-filtered data. Discriminant analyses (Production Facility v11.0.0, SPSS Inc., Chicago, Illinois) were used to assess the relative discriminatory powers of the four acoustic energy parameters to resolve levels of RV and benthic habitat class, using the 20-80 percentile-filtered data.

\section{RESULTS}

\section{Lidar Reef-Volume: Interpretation of Habitat Class}

The rankings and cumulative frequencies of the lidar-derived reef-volume (RV) conformed to the visually apparent topographic complexity of the eight lidar-delineated benthic habitat classes (Figure 4). The featureless sand, deep sand, and sand over hardbottom habitats grouped on the low end of RV measurements and the topographically complex linear reef and spur and groove habitats grouped on the high end of RV measurements. Tukey HSD testing $(\alpha=0.05)$, with modification to control for sample size, showed that the means of RV differed significantly between $89.3 \%$ of the $\mathrm{k} \cdot(\mathrm{k}-1) / 2=21$ habitat comparisons (Table 1$)$. This is not to say that lidar reef-volume is a suitable stand-alone parameter for benthic habitat classification, as there is considerable overlap between many habitat categories.

\section{E1 and E2: Interpretation of Lidar Reef-Volume}

The relationships between RV:E1 and RV:E2 were thoroughly consistent between the 38 and $418 \mathrm{kHz}$ signals, judged by the cumulative frequencies and rankings of $\mathrm{E} 1$ and $\mathrm{E} 2$ at seven arbitrarilyselected ranges of RV (Figure 5). The E1s of both frequencies were positively correlated with RV, whereas both E2s were negatively correlated. Tukey HSD testing $(\alpha=0.05)$ showed significant differences between the means of all four acoustic parameters for most of the seven RV ranges (Table 2). The E2 parameters of both frequencies provided greater discrimination; significant differences were found in $85.7 \%$ and $81.0 \%$ of the $\mathrm{k} \cdot(\mathrm{k}-1) / 2=21$ comparisons for the 38 and $418 \mathrm{kHz}$ E2 parameters, respectively, compared to $66.7 \%$ and $61.9 \%$ for the 38 and $418 \mathrm{kHz} \mathrm{E} 1$ parameters. The greater discrimination of $\mathrm{E} 2$ at both acoustic frequencies was also evidenced by the greater values of standardized canonical discriminant function coefficients (Table 3a). The greater acuity of the E2 parameter is presumably a result of both $\mathrm{E} 1$ and $\mathrm{E} 2$ being controlled by seabed roughness, affecting the multi-path $\mathrm{E} 2$ more than the single-path E1. None of the four acoustic parameters showed signs of instability over increasingly topographically complex terrain as judged by coefficients of variation calculated for each of the seven RV ranges (Table 4). 

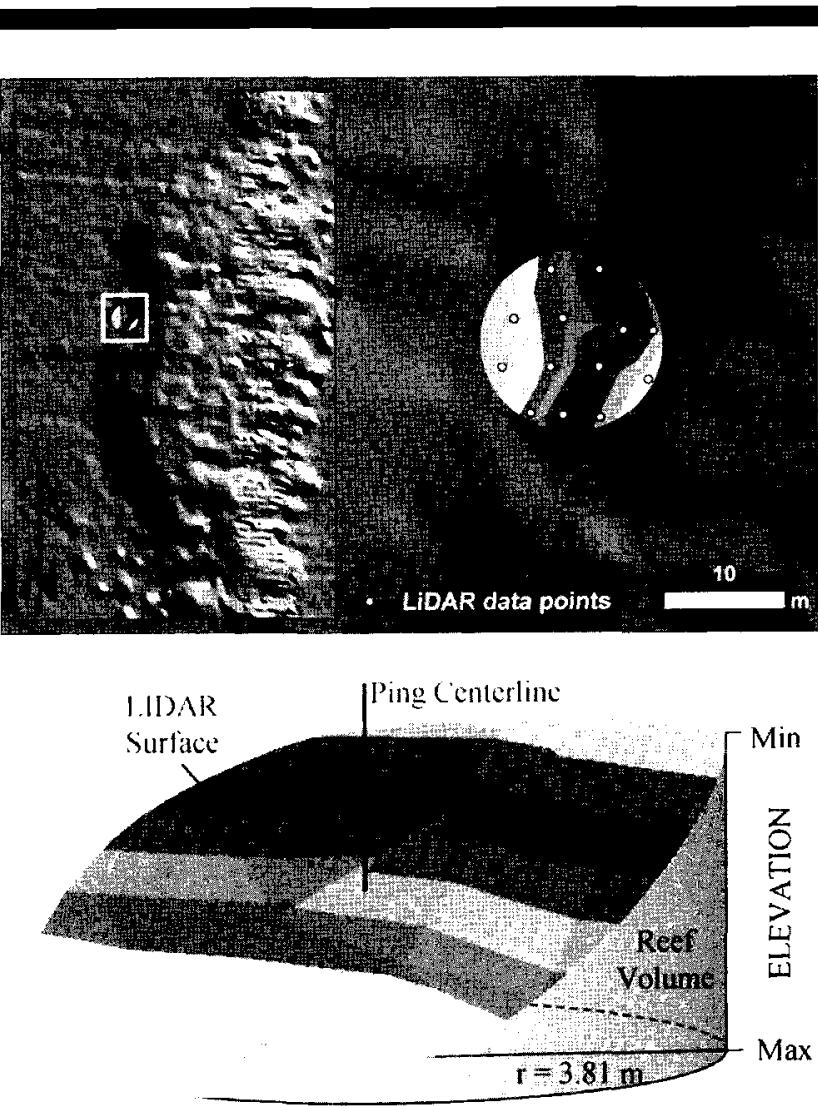

Figure 3. Example of reef-volume calculation. (Above) A single $7.62 \mathrm{~m}$ diameter search buffer overlying lidar bathymetry. (Close-Up) Twelve typical lidar data points defining 3D lidar surface used for GIS-measurement of reef-volume $\left(\mathrm{m}^{3}\right)$. (Below) lllustration of reef-volume, defined as the volume beneath a lidar surface bound by a $7.62 \mathrm{~m}$ diameter cylinder with height equal to $\Delta$ Elevation. Reef-volume in this example is $133 \mathrm{~m}^{3}$ (90th percentile of study area)

\section{E1 and E2: Interpretation of Habitat Class}

The four acoustic energy parameters ordered the eight benthic habitat classes similarly, as judged by the cumulative frequencies and rankings of $\mathrm{E} 1$ and $\mathrm{E} 2$ (Figure 6, Table 5). As with $\mathrm{RV}$, the rankings of $\mathrm{E} 1$ and $\mathrm{E} 2$ were inverted: the E1s were, in general, positively correlated with topographic complexity and the E2s negatively so. While the E1s and E2s of both frequencies ranked the habitats similarly, these differed markedly from the rankings obtained from RV (Table 5). Tukey HSD testing ( $\alpha=0.05$ ) confirmed significant differences between the means of all four acoustic parameters for most of the benthic habitat comparisons. Significant differences were found in $96.4 \%, 89.3 \%, 92.9 \%$, and $92.9 \%$ of the $\mathrm{k} \cdot(\mathrm{k}-1) / 2=28$ comparisons for $38 \mathrm{kHz}$ E1, $38 \mathrm{kHz}$ E2, $418 \mathrm{kHz}$ E1 and $418 \mathrm{kHz}$ E2, respectively (Table 6).

\section{Epibenthic Biota: Influence and Detection}

The ordering of the eight habitat classes by RV conformed to the visually apparent topographic complexity of the habitats
(Figure 4), and the ordering of the seven levels of RV by the 38 and $418 \mathrm{kHz}$ E1 and E2 were uniformly correct (Figure 5). For the acoustics to have ranked habitats differently than the RV metric (Figure 4, Table 5), some factor other than topographic complexity must be informing the acoustic parameters, e.g., locally abundant and variable colonies of erect gorgonians. The between-habitat differences in gorgonian abundance were estimated by processing the $418 \mathrm{kHz}$ data in BioSonics EcoSAV software to produce estimates of plant canopy height (Table 7). Ground-truthing within the survey area generally supported the EcoSAV predictions. The colonized pavement habitat, which had much higher values of E1 than would be expected from its RV ranking, was found to have the highest EcoSAV-predicted gorgonian abundance. The ridge habitat, which ranked third by RV but only sixth and fifth by the 38 and $418 \mathrm{kHz}$ E1 values, ranked fifth by predicted gorgonian abundance. The spur and groove habitat, which had the highest average RV but ranked fifth by both E1 values, ranked sixth by predicted gorgonian abundance. All suggest that signal scattering within the canopy of erect gorgonian colonies was significantly informing the values of the $\mathrm{E} 1$ parameter.

\section{E1:E2 Bottom Ratio: Habitat Classification}

For the purpose of assessing acoustic classification accuracy, the original eight benthic habitat classes were consolidated to five after plotting the E1:E2 data, as three pairs of habitat classes were found to occupy the same E1:E2 space (Figure 7). Two main groupings of benthic habitats can be observed. Group 1 included the sand, deep sand, and sand over hardbottom classes, which exhibited a general upward trend along the E1:E2 diagonal. Group 2 included the remaining five reefal benthic habitat classes, which exhibited a general downward trend along the E1:E2 diagonal. The correlation coefficient $(r)$ of the depth-normalized, log-transformed E1 and $\mathrm{E} 2$ values was significant $(\mathrm{P}<0.0005)$ for both groups and both frequencies. For Group 1, $r=0.44$ at $38 \mathrm{kHz}$ and 0.34 at $418 \mathrm{kHz}$. For Group 2, r $=-0.59$ at $38 \mathrm{kHz}$ and -0.79 at $418 \mathrm{kHz}$. The accuracy coefficient Te was significantly greater at $418 \mathrm{kHz}$ than at $38 \mathrm{kHz}$, 0.475 versus $0.395(\mathrm{p}<0.0005$, Table $8 \mathrm{a}-\mathrm{b})$. Passing E1 and E2 data

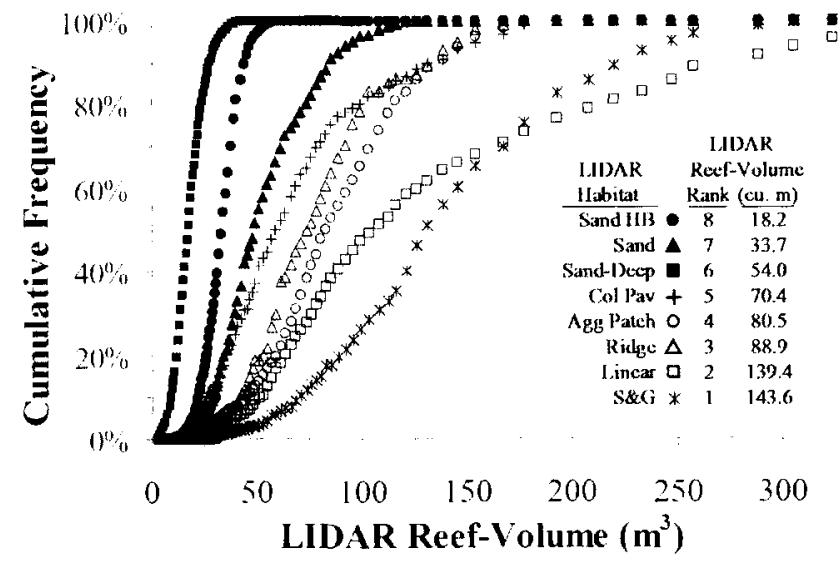

Figure 4. Cumulative frequencies and averages of reef-volume (lidar-derived proxy for topographic complexity) for the eight lidar-delineated benthic habitat classes. Reef-volume is defined as the volume beneath a lidar surface bound by a $7.62 \mathrm{~m}$ diameter cylinder with height equal to $\Delta$ Elevation. 

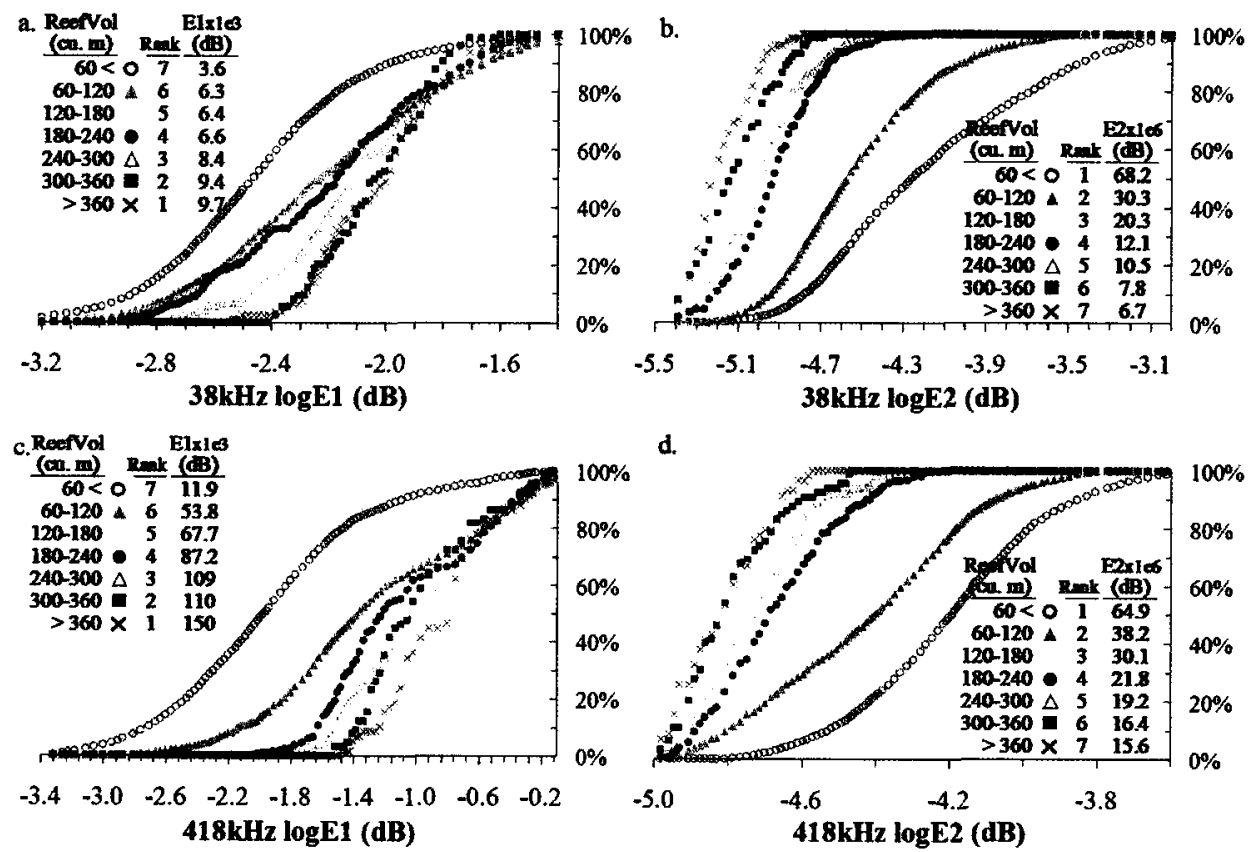

Figure 5a-d. Cumulative frequencies and averages of the depth-normalized and log-transformed acoustic energy parameters E1 (tail of $1^{\text {st }}$ echo) and E2 (complete $2^{\text {nd }}$ echo) for the seven arbitrarily-selected ranges of lidar reef-volume. Ranks are in order of increasing average values of acoustic energy parameters.

through the additional 20 and 80 percentile filters greatly improved classification accuracies, to 0.778 at $418 \mathrm{kHz}$ versus 0.747 at 38 $\mathrm{kHz}$ (Table 8c-d). Again, classification accuracy was significantly greater at $418 \mathrm{kHz}(\mathrm{p}=0.0192)$.

\section{DISCUSSION}

The findings of this study indicate that either 38 or $418 \mathrm{kHz}$ single-beam data can be used to classify coral reef benthic habitats using the multi-echo E1:E2 bottom ratio method. That two frequencies at the extremes typically used for single-beam

Table 1. Summary of Tukey HSD testing (with modification to control for sample size) of lidar reef-volume ( $\pm 3 \sigma$ outliers removed) for the eight lidardelineated benthic habitat classes. Significant differences $(\alpha=0.05)$ between means denoted by ' $\neq$ '.

\begin{tabular}{|c|c|c|c|c|c|c|c|}
\hline LIDAR & Reefvolum & - Tuk & $y^{\prime}$ & & eans D & illerent $=$ & $89.3 \%$ \\
\hline $\mathrm{n}$ & $2090 \quad 2351$ & 716 & 405 & 109 & 849 & 996 & 591 \\
\hline $\begin{array}{l}\text { Ilabital } \\
\text { Class }\end{array}$ & $\begin{array}{c}\text { Sand } \\
\mathrm{HB}\end{array}$ Sand & $\begin{array}{l}\text { Sand . } \\
\text { Deep }\end{array}$ & $\begin{array}{l}\text { Col } \\
\text { Pav }\end{array}$ & $\begin{array}{l}\text { Agg } \\
\text { Patch }\end{array}$ & Ridgc & $\begin{array}{l}\text { I.incar } \\
\text { Reer }\end{array}$ & S\&G \\
\hline $\begin{array}{l}\text { Sand } \\
\mathrm{HB}\end{array}$ & $\neq$ & $\neq$ & $\neq$ & $\neq$ & $\neq$ & $\neq$ & $\neq$ \\
\hline Sand & & $\neq$ & $\neq$ & $\neq$ & $\neq$ & $\neq$ & $\neq$ \\
\hline $\begin{array}{l}\text { Sand - } \\
\text { Decp }\end{array}$ & & & $\neq$ & $\neq$ & $\neq$ & $\neq$ & $\neq$ \\
\hline $\begin{array}{l}\text { Col } \\
\text { Pav }\end{array}$ & & & & - & $\neq$ & $\neq$ & $\neq$ \\
\hline $\begin{array}{l}\text { Agg } \\
\text { Palch }\end{array}$ & & & & & & $\neq$ & $\neq$ \\
\hline Ridge & & & & & & $\neq$ & $\neq$ \\
\hline $\begin{array}{l}\text { 1.inear } \\
\text { Reef }\end{array}$ & & & & & & & 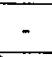 \\
\hline S\&G & & & & & & & \\
\hline
\end{tabular}

AGDS should yield similar results is not entirely surprising, as Brekhovskikh and Lysanov (1982) reported that seabed roughness begins to play a dominant role over sediment class at frequencies greater than a few $\mathrm{kHz}$. A precondition to the findings of this study is that $\mathrm{E} 1$ and $\mathrm{E} 2$ values must be normalized to a reference depth (Dommisse et al., 2005), preferably during signal processing before E1 and E2 are calculated, or empirically after the fact as presented here (Figure 2). Another critical prerequisite for categorization of

Table 2. Summary of Tukey HSD testing (with modification to control for sample size) of depth-normalized and log-transformed acoustic energy parameters E1 (tail of 1 st echo) and E2 (complete $2^{\text {nd }}$ echo) for the seven arbitrarily-selected ranges of lidar reef-volume $\left(\mathrm{m}^{3}\right) . \pm 3 \sigma$ outliers removed for normality. Significant differences $(\alpha=0.05)$ between means denoted by ' $f$ '. $38 \mathrm{kHz}$ E1 and E2 results in upper- and lower-left corners; $418 \mathrm{kHz} E 1$ and $E 2$ results in upper-and lower-right corners, respectively.

\begin{tabular}{|c|c|c|c|c|c|c|c|c|}
\hline $\log 38 \mathrm{k} H \mathrm{lz} n$ & 5350 & $1+96$ & 661 & 239 & 139 & 74 & 81 & \\
\hline $\log 2418 \mathrm{kH}$ & 4877 & 1381) & 591 & 215 & 127 & 615 & 58 & \\
\hline $\begin{array}{c}\text { Reef } \\
\text { Volume }\end{array}$ & $60<$ & $60-120$ & $120-180$ & $180-240$ & $240-300$ & $300-360$ & $>360$ & \\
\hline $60<$ & $.3851418 \mathrm{E} 1$ & $\neq$ & $\neq$ & $\neq$ & $\neq$ & $\neq$ & $\neq$ & $\neq$ \\
\hline & $38 \mathrm{E} 2418 \mathrm{E} 2$ & $\neq$ & $\neq$ & $\neq$ & $\neq$ & $\neq$ & $\neq$ & $\neq$ \\
\hline $60-120$ & & & 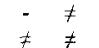 & $\begin{array}{ll}- & \neq \\
7 & \neq\end{array}$ & $\begin{array}{l}\neq \neq \\
\neq\end{array}$ & $\begin{array}{l}\neq \\
\neq\end{array}$ & $\neq$ & $\begin{array}{l}f \\
F\end{array}$ \\
\hline $120-180$ & & & & $\begin{array}{l}- \\
\neq \quad\end{array}$ & $\begin{array}{l}\neq \neq \\
\neq \quad \neq\end{array}$ & $\begin{array}{l}\neq \\
\neq\end{array}$ & $\begin{array}{ll}\neq & 7 \\
\neq & \neq\end{array}$ & $\begin{array}{l}7 \\
\neq \\
7\end{array}$ \\
\hline $180-240$ & & & & & - & $\begin{array}{l}\neq \\
\neq \\
\end{array}$ & $\begin{array}{l}\neq \\
\neq\end{array}$ & 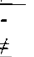 \\
\hline $240-300$ & & & & & & - & & - \\
\hline $300-360$ & & & & & & & $\begin{array}{l}- \\
-\end{array}$ & - \\
\hline$>360$ & & & & & & & & \\
\hline
\end{tabular}


Table 3. Standardized canonical discriminant function coefficients of the first discriminant function for (a) the seven arbitrarily-selected levels of lidar reef-volume, and (b) the five consolidated benthic habitat classes used for the E1:E2 bottom ratio seabed classification method. Predictor variables were depth-normalized and log-transformed values of acoustic energy parameters E1 and E2.

\begin{tabular}{|c|c|c|c|c|c|c|c|c|}
\hline \multirow[b]{3}{*}{$(\mathrm{kH} \%)$} & \multicolumn{8}{|c|}{ Standardized Canonical Discriminant Function Coefficents } \\
\hline & \multicolumn{4}{|c|}{$\begin{array}{l}\text { (a) LIDAR Reef-Volume (7 Groups) } \\
\text { lst Discriminant Function }\end{array}$} & \multicolumn{4}{|c|}{$\begin{array}{l}\text { (b) LIDAR Habitat Class ( } 5 \text { Groups } \\
1 \text { st Discriminant Function }\end{array}$} \\
\hline & $\log E 1$ & $\log \mathrm{E}: 2$ & Variance & $\begin{array}{l}\text { Canonical } \\
\text { Correlation }\end{array}$ & $\log \mathbf{E} \mathbf{I}$ & $\log \mathbf{E} 2$ & Variance & $\begin{array}{l}\text { Canonical } \\
\text { Correlation } \\
\end{array}$ \\
\hline 38 & -0.471 & 0.855 & $98.4 \%$ & 0.538 & -0.580 & 0.836 & $76.7 \%$ & 0.912 \\
\hline 418 & -0.570 & 0.704 & $97.8 \%$ & 0.608 & 0.820 & -0.629 & $94.2 \%$ & 0.952 \\
\hline
\end{tabular}

coral reef habitats is stable and meaningful values of E1 and E2 over rocky, rough terrain. While the findings of this study indicate that the values of E1 and E2 were sufficiently stable over the reefal habitats to allow for habitat categorization, there is evidence that the acoustics might have been approaching a limit, as discussed in the following section.

\section{Limits of Acoustic Discrimination}

The 38 and $418 \mathrm{kHz}$ Els ranked the seven levels of RV in strict ascending order and the $\mathrm{E} 2 \mathrm{~s}$ ranked $\mathrm{RV}$ in strict descending order (Figure 5). The increase in E1 with increasing RV agrees with the general empirical rationale for seabed classification, that a rougher seabed surface creates more scattering of the transmitted echo and increases the proportion of signal returning to the transducer in the second half of the first echo (Burczynski, 1999). The decrease in E2 with increasing RV (and by extension, increasing seabed hardness)
Table 4. Coefficients of variation of the seven arbitrarily-selected levels of lidar-derived reef-volume, calculated individually for each of the four depthnormalized and log-transformed acoustic energy parameters.

Coefficient of Variation $(\sigma / \mu \cdot 100)$ of Log-Transformed E Values LIDAR Reef-Volume Levels $\left(\mathrm{m}^{3}\right)$

\begin{tabular}{|c|c|c|c|c|c|c|c|c|}
\hline$(\mathrm{kHz})$ & Echo & $60<$ & $60-120$ & $120-180$ & $180-240$ & $240-300$ & $300-360$ & $>360$ \\
\hline 38 & E1 & -14.7 & -18.1 & -16.6 & -16.0 & -14.9 & -9.2 & -10.9 \\
\hline 38 & E2 & -12.1 & -7.8 & -6.4 & -4.5 & -4.2 & -3.7 & -2.9 \\
\hline 418 & El & -32.7 & -51.9 & -44.0 & -45.4 & -45.5 & -37.5 & -40.0 \\
\hline 418 & E2 & -6.1 & -6.2 & -5.0 & -3.6 & -3.1 & -2.8 & -2.4 \\
\hline
\end{tabular}

could at first be seen as contradictory, but specular reflection is related to seabed hardness only for a flat surface (Burczynski, 1999). The alternative interpretation is that $E 2$ was also controlled primarily by seabed roughness, i.e. the incoherent backscatter was less likely to complete the multi-path circuit. Notwithstanding the mechanisms controlling E2, it is clear that the acoustic parameters agreed with RV in judging topographic complexity. However, Tukey HSD analyses revealed only one significant difference between the $240-300,300-360$, and $>360 \mathrm{~m}^{3}$ ranges of RV (Table 2), indicating the discriminatory capability of all four acoustic parameters diminished at the upper ranges of topographic complexity. Lurton and Pouliquen (1992) and McKinney and Anderson (1964) reported instability of acoustic backscatter over increasingly rough surfaces, but in this study none of the four acoustic parameters exhibited instability at the higher ranges of RV, as judged by coefficients of variation (Table 4).

Another possible explanation is that at the upper ranges of RV the horizontal scale of seabed variability dropped below what was
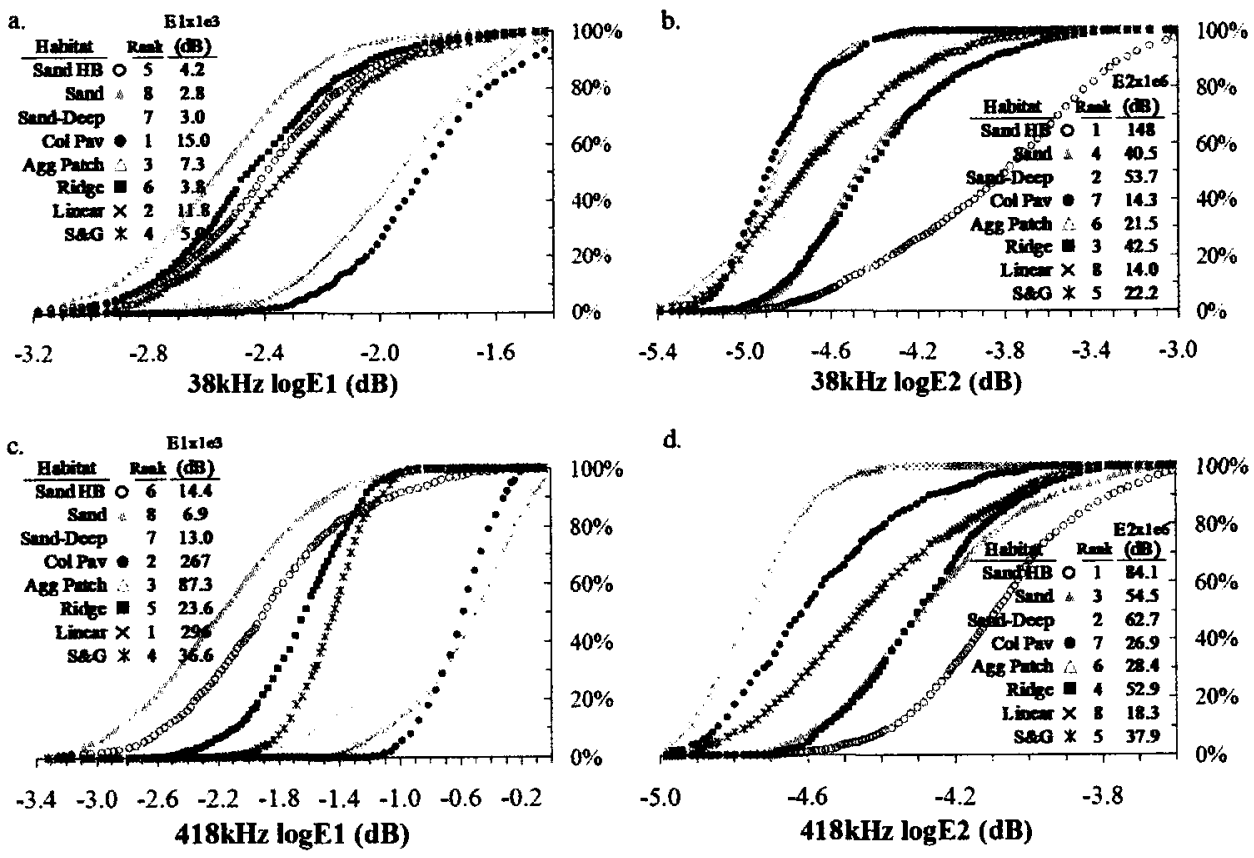

Figure 6a-d. Cumulative frequencies and averages of the depth-normalized and log-transformed acoustic energy parameters El (tail of $1^{\text {st }}$ echo) and E2 (complete $2^{\text {nd }}$ echo) for the eight lidar-delineated benthic habitat classes. Ranks are in order of increasing average values of acoustic energy parameters. 
Table 5. Summary of the ranking orders of the eight lidar-delineated benthic habitat classes by the depth-normalized and log-transformed 38 and $418 \mathrm{kHz}$ acoustic energy parameters, and by reef-volume, the lidar-derived proxy for topographic complexity.

\begin{tabular}{|c|c|c|c|c|c|c|c|c|}
\hline $\begin{array}{l}38 \mathrm{kHz} \text { E1 } \\
\text { Ascending }\end{array}$ & Sand & $\begin{array}{l}\text { Sand- } \\
\text { Deep }\end{array}$ & Ridge & $\begin{array}{c}\text { Sand } \\
\text { over HB }\end{array}$ & $\begin{array}{l}\text { Spur \& } \\
\text { Groove }\end{array}$ & $\begin{array}{l}\text { Agg } \\
\text { Patch }\end{array}$ & $\begin{array}{c}\text { Linear } \\
\text { Reef }\end{array}$ & Col Pav \\
\hline $\begin{array}{c}38 \mathrm{kH} \angle \mathrm{E} 2 \\
\text { Descending }\end{array}$ & $\begin{array}{c}\text { Sand } \\
\text { over HB }\end{array}$ & $\begin{array}{l}\text { Sand- } \\
\text { Deep }\end{array}$ & Ridge & Sand & $\begin{array}{l}\text { Spur \& } \\
\text { Groove }\end{array}$ & $\begin{array}{l}\text { Agg } \\
\text { Patch }\end{array}$ & Col Pav & $\begin{array}{c}\text { Linear } \\
\text { Reef }\end{array}$ \\
\hline $\begin{array}{l}\text { 418kHz EI } \\
\text { Ascending }\end{array}$ & Sand & $\begin{array}{l}\text { Sand- } \\
\text { Deep }\end{array}$ & $\begin{array}{c}\text { Sand } \\
\text { over HB }\end{array}$ & Ridge & $\begin{array}{l}\text { Spur \& } \\
\text { Gronve }\end{array}$ & $\begin{array}{c}\text { Agg } \\
\text { Patch }\end{array}$ & Col Pav & $\begin{array}{l}\text { Linear } \\
\text { Reef }\end{array}$ \\
\hline $\begin{array}{l}\text { 418kHz E2 } \\
\text { Descending }\end{array}$ & $\begin{array}{c}\text { Sand } \\
\text { over IIB }\end{array}$ & $\begin{array}{l}\text { Sand- } \\
\text { Deep }\end{array}$ & Sand & Ridge & $\begin{array}{l}\text { Spur \& } \\
\text { Groove }\end{array}$ & $\begin{array}{l}\text { Agg } \\
\text { Patch }\end{array}$ & Col Pav & $\begin{array}{l}\text { Linear } \\
\text { Reef }\end{array}$ \\
\hline $\begin{array}{l}\text { LIDAR RV } \\
\text { Ascending }\end{array}$ & $\begin{array}{c}\text { Sand } \\
\text { over H13 }\end{array}$ & Sand & $\begin{array}{l}\text { Sand- } \\
\text { Dcep }\end{array}$ & Col Pav & $\begin{array}{c}\text { Agg } \\
\text { Patch }\end{array}$ & Ridge & $\begin{array}{c}\text { Linear } \\
\text { Reef }\end{array}$ & $\begin{array}{l}\text { Spur \& } \\
\text { Groove }\end{array}$ \\
\hline
\end{tabular}

detectable by the acoustic footprint (Rukavina, 1997). The mean depth of records with values of RV exceeding $240 \mathrm{~m}^{3}$ was $20.3 \mathrm{~m}$, at which the diameter of the 38 and $418 \mathrm{kHz}$ footprints would be $3.6 \mathrm{~m}$ and $2.3 \mathrm{~m}$, respectively. The repeating units of relict coral spires and surrounding valleys, typical of the roughest areas of the linear and spur and groove reefs, did indeed appear in the groundtruthing videos to occur at a sub-footprint scale, though controlled experimentation would be required for confirmation.

Alternatively (or additionally), the highest values of RV could have coincided with areas characterized by inclinations large enough to interfere with echo acquisition. Von Szalay and McConnaughey (2002) reported that bottom inclinations exceeding $5-8^{\circ}$ resulted in a total breakdown of QTC View classifications for two QTC View systems utilizing $38 \mathrm{kHz}$ transducers with beamwidths of $7^{\circ} \times 7^{\circ}$ and $9^{\circ} \times 13^{\circ}$, due to increased echo duration and side-lobe interactions affecting the shape of the first echo
Table 6. Summary of Tukey HSD testing (with modification to control for sample size) of depth-normalized and log-transformed acoustic energy parameters E1 (tail of 1st echo) and E2 (complete $2^{\text {nd }}$ echo) for the eight lidar-delineated benthic habitat classes. $\pm 3 \sigma$ outliers removed for normality. Significant differences ( $\alpha=0.05$ ) between means denoted by ' $\neq$ '. $38 \mathrm{kHz} E 1$ and $E 2$ results in upper-and lower-left corners, $418 \mathrm{kHz} E 1$ and $E 2$ results in upper-and lower-right comers, respectively.

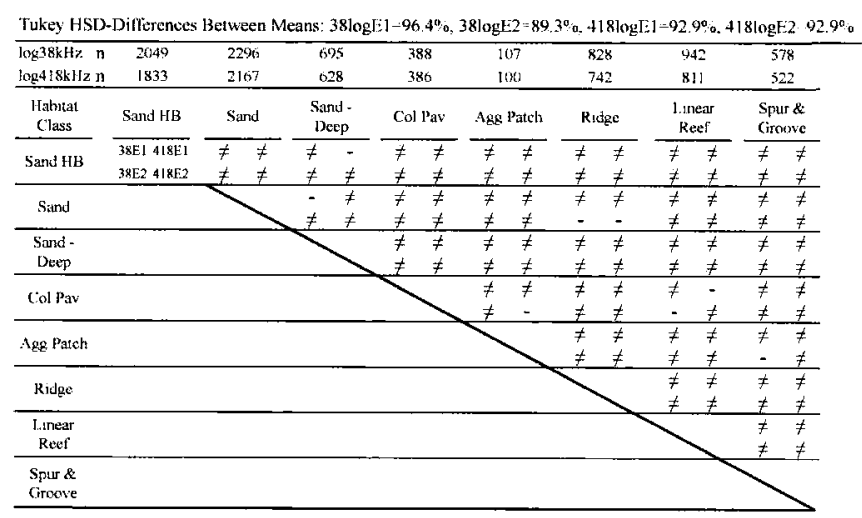

return. Gleason et al. (2006) also observed highest QTC acoustic variability at the greatest substratum inclination. But once again, the coefficients of variation did not indicate a total breakdown. And unlike observations from Hamilton, Mulhearn, and Poeckert (1999) on the Great Barrier Reef, the E2 value was not absent or erratic but simply smaller over the reefal habits compared to the sand habitats.

If sub-footprint seabed roughness or high inclinations were the only factors suppressing values of $\mathrm{E} 2$ over reefal terrain, one

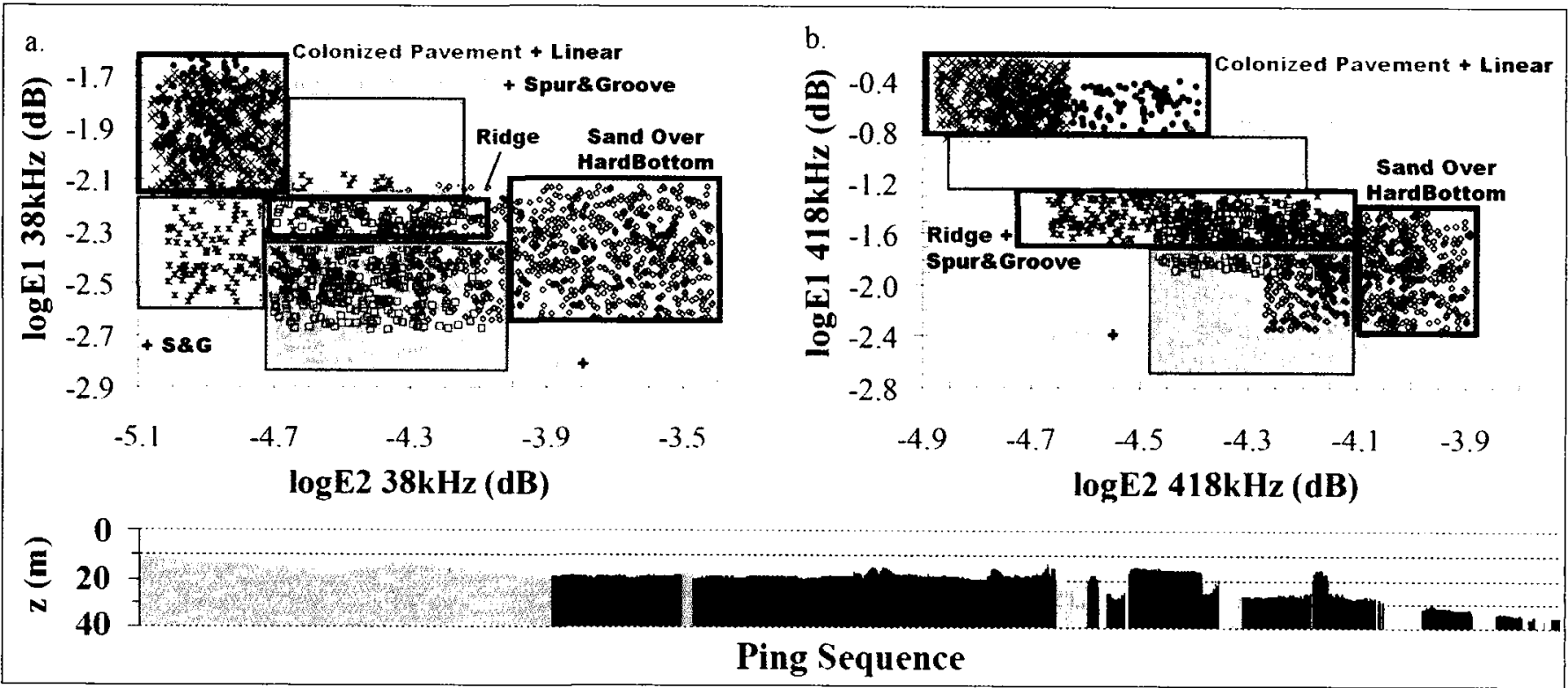

Figure 7. Depth-normalized and log-transformed values of the acoustic energy parameters E1 and E2, reduced to a 20-80 percentile sub-set, plotted in the XY Cartesian space of the E1:E2 bottom ratio classification method for the (a) $38 \mathrm{kHz}$ signal and (b) $418 \mathrm{kHz}$ signal. Boxes denote E1:E2 boundaries used for accuracy assessment of training dataset, with corresponding labels denoting lidar-delineated benthic habitat class membership within each. (Below) Depth profile of the eight lidar-delineated benthic habitat classes in order of acquisition and belonging to the 20-80 percentile sub-set. 
Table 7. Average predicted canopy heights of the eight lidar-delineated benthic habitat classes obtained from processing the $418 \mathrm{kHz}$ signal with BioSonics EcoSAV software. Average canopy height is a surrogate measure of abundance of erect colonies of gorgonians.

EcoSAV Predicted Canopy Height $(\mathrm{m})$
Sand
$\frac{\text { Sand }}{0.00} \frac{\text { HB }}{0.00} \frac{\text { Deep }}{0.06} \frac{\text { Ridge }}{0.11} \frac{\text { Patch }}{0.26} \frac{\text { Groove }}{0.29} \frac{\text { Reef }}{0.34} \frac{\text { Pav }}{0.36}$

would expect the flattest, hardest, and least colonized regions of the reefal habitats to occasionally produce values of E2 greater than those recorded over the softer sand habitats. However, at $418 \mathrm{kHz}$ only $2.2 \%$ of the E2 records recorded over the five reefal habitats exceeded the 90th percentile of E2 values recorded over the three sand habitats. This suggests that the cause of the consistently smaller values of $\mathrm{E} 2$ recorded over reefal habitats was the result of seabed roughness being the primary factor controlling both E1 and E2. The potential for the harder substrata of the reefal habitats to produce large values of $\mathrm{E} 2$ was overshadowed by the greater proportion of incoherent backscatter produced by the combined contribution of seabed roughness and epibenthic biota. The incoherent backscatter from the hard but rough reefal substrata increased the value of $\mathrm{E} 1$, in accordance with the general empirical rationale for seabed classification, and likewise decreased the value of E2, as the incoherent backscatter would be less likely to complete the multipath circuit. Similar results were reported by Riegl et al. (2007), and both suggest that the values of E1 and E2 recorded over the rocky, rough habitats are indeed meaningful, although the effects of sub-footprint seabed roughness and high seabed inclination are likely contributing to the diminishing acoustic acuity observed at the highest levels of seabed roughness.

\section{Acoustic Discrimination: E1:E2}

The orientation of the sand, deep sand, and sand over hardbottom habitats along an upward diagonal in E1:E2 space is consistent with findings from RoxAnn surveys (Chivers, Emerson, and Burns, 1990; Greenstreet et al., 1997; Magorrian, Service, and Clarke, 1995; Wilding, Sayer, and Provost, 2003), and agrees with the rationale of harder ground having a greater capability of exhibiting roughness (Chivers, Emerson, and Burns, 1990; Wilding, Sayer, and Provost, 2003). The remaining five reefal habitats, rather than continuing up and to the right as did the gravel and rock classes of Chivers, Emerson, and Burns (1990), are instead up and to the left of the sand habitats (i.e., higher E1, lower E2). The relative orientations of individual reefal habitats in E1:E2 space illustrates the central theme of the preceding section; E1 and E2 are both primarily informed by the combined scattering from substrate plus biotic components. For example, the relatively flat colonized pavement habitat grouped with the linear reef habitat in the upperleft corner of E1:E2 Cartesian space (Figure 7). These two habitats differ markedly in inclination and rugosity but have in common a high EcoSAV-predicted gorgonian abundance. Furthermore, the two habitats are less intermingled at $418 \mathrm{kHz}$ than at $38 \mathrm{kHz}$, presumably due to the shorter wavelength of the $418 \mathrm{kHz}$ signal being more sensitive to between-habitat differences in gorgonian abundance. A second example is how the rugose spur and groove

Table 8. Error matrices for E1:E2 bottom method seabed classification of depth-normalized and log-transformed E1:E2 pairs into the lidar-delineated benthic habitat classes for (a-b) all E1:E2 data and (c-d) after passing E1 and E2 through additional 20-80 percentile filters.

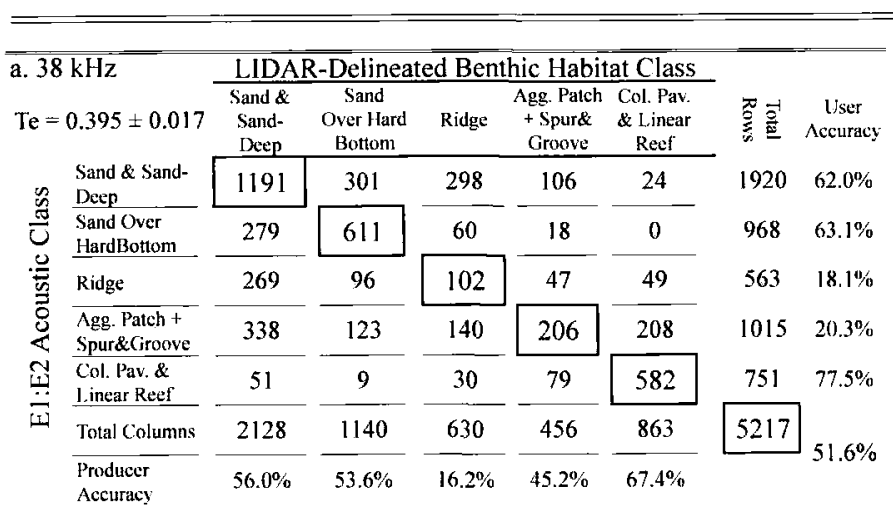

\begin{tabular}{|c|c|c|c|c|c|c|c|c|}
\hline \multirow{2}{*}{\multicolumn{2}{|c|}{$\begin{array}{l}\text { c. } 38 \mathrm{kHz} \\
\mathrm{T}_{\mathrm{e}}=0.747 \pm 0.018\end{array}$}} & \multicolumn{7}{|c|}{ LIDAR-Delineated Benthic Habitat Class } \\
\hline & & $\begin{array}{l}\text { Sand \& } \\
\text { Sand- } \\
\text { Deep }\end{array}$ & $\begin{array}{c}\text { Sand } \\
\text { Over Hard } \\
\text { Bottom } \\
\end{array}$ & Ridge & $\begin{array}{l}\text { Agg. Patch } \\
\text { + Spur\& } \\
\text { Groove }\end{array}$ & $\begin{array}{l}\text { Col. Pav } \\
\text { \& Linear } \\
\text { Reef }\end{array}$ & 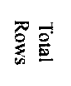 & $\begin{array}{c}\text { User } \\
\text { Accuracy }\end{array}$ \\
\hline \multirow{7}{*}{ 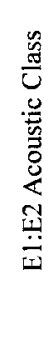 } & $\begin{array}{l}\text { Sand \& Sand- } \\
\text { Deep }\end{array}$ & 990 & 104 & 217 & 50 & 0 & 1361 & $72.7 \%$ \\
\hline & $\begin{array}{l}\text { Sand Over } \\
\text { HardBottom }\end{array}$ & 0 & 573 & 0 & 0 & 0 & 573 & $100.0 \%$ \\
\hline & Ridge & 64 & 45 & 95 & 40 & I & 245 & $38.8 \%$ \\
\hline & $\begin{array}{l}\text { Agg. Patch + } \\
\text { Spur\&Groove }\end{array}$ & 0 & 7 & 0 & 145 & 9 & 161 & $90.1 \%$ \\
\hline & $\begin{array}{l}\text { Col. Pav. \& } \\
\text { I. inear Reef }\end{array}$ & 0 & 0 & 0 & 39 & 471 & 510 & $92.4 \%$ \\
\hline & Total Columns & 1054 & 729 & 312 & 274 & 481 & 2850 & \\
\hline & $\begin{array}{l}\text { Producer } \\
\text { Accuracy }\end{array}$ & $93.9 \%$ & $78.6 \%$ & $30.4 \%$ & $52.9 \%$ & $97.9 \%$ & & \\
\hline
\end{tabular}

\begin{tabular}{|c|c|c|c|c|c|c|c|c|}
\hline \multicolumn{2}{|c|}{ b. $418 \mathrm{kHz}$} & LID & -Delinea & d Bent & hic Habit & at Class & \multirow[b]{2}{*}{ 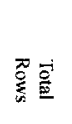 } & \multirow[b]{2}{*}{$\begin{array}{c}\text { User } \\
\text { Aceuracy }\end{array}$} \\
\hline \multicolumn{2}{|c|}{$\mathrm{Te}=0.475 \pm 0.018$} & $\begin{array}{l}\text { Sand \& } \\
\text { Sand- } \\
\text { Deep }\end{array}$ & $\begin{array}{l}\text { Sand } \\
\text { Over Hard } \\
\text { Botlom }\end{array}$ & $\begin{array}{l}\text { Ridge + } \\
\text { Spurk } \\
\text { Groove }\end{array}$ & $\begin{array}{l}\text { Aggregate } \\
\text { Patch Reef }\end{array}$ & $\begin{array}{l}\text { Col. Pav. } \\
\text { \& l.inear } \\
\text { Reel }\end{array}$ & & \\
\hline \multirow{6}{*}{ 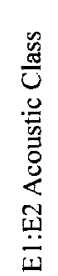 } & $\begin{array}{l}\text { Sand \& Sand- } \\
\text { Deep }\end{array}$ & 1098 & 443 & 221 & 3 & 0 & 1765 & $62.2 \%$ \\
\hline & $\begin{array}{l}\text { Sand Over } \\
\text { IlardBotom }\end{array}$ & 272 & 406 & 109 & 3 & 0 & 790 & $51.4 \%$ \\
\hline & $\begin{array}{l}\text { Ridge }+ \\
\text { Spur\&Groove }\end{array}$ & 360 & 170 & 547 & 14 & 22 & 1113 & $49.1 \%$ \\
\hline & $\begin{array}{l}\text { Aggregate } \\
\text { Patch Reef }\end{array}$ & 47 & 54 & 107 & 49 & 142 & 399 & $12.3 \%$ \\
\hline & $\begin{array}{l}\text { Col. Pav. \& } \\
\text { Linear Reef }\end{array}$ & 0 & 21 & 0 & 19 & 667 & 707 & \multirow{3}{*}{$\begin{array}{l}94.3 \% \\
58.0 \%\end{array}$} \\
\hline & Total Columns & 1777 & 1094 & 984 & 88 & 831 & 4774 & \\
\hline & & $61.8 \%$ & $37.1 \%$ & $55.6 \%$ & $55.7 \%$ & $80.3 \%$ & & \\
\hline
\end{tabular}

\begin{tabular}{|c|c|c|c|c|c|c|c|c|}
\hline \multirow{2}{*}{\multicolumn{2}{|c|}{$\begin{array}{l}\text { d. } 418 \mathrm{kHz} \\
\mathrm{T}_{\mathrm{e}}=0.778 \pm 0.018\end{array}$}} & \multicolumn{7}{|c|}{ LIDAR-Delineated Benthic Habitat Class } \\
\hline & & $\begin{array}{l}\text { Sand \& } \\
\text { Sand- } \\
\text { Deep }\end{array}$ & $\begin{array}{c}\text { Sand } \\
\text { Over Hard } \\
\text { Bottom }\end{array}$ & $\begin{array}{l}\text { Ridge + } \\
\text { Spur\& } \\
\text { Groove }\end{array}$ & $\begin{array}{l}\text { Aggregate } \\
\text { Patch Reef }\end{array}$ & $\begin{array}{l}\text { Col. Pav. } \\
\text { \& Linear } \\
\text { Reef }\end{array}$ & 营预 & $\begin{array}{c}\text { User } \\
\text { Accuracy }\end{array}$ \\
\hline \multirow{7}{*}{ 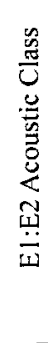 } & $\begin{array}{l}\text { Sand \& Sand- } \\
\text { Deep }\end{array}$ & 941 & 212 & 77 & 0 & 0 & 1230 & $76.5 \%$ \\
\hline & $\begin{array}{l}\text { Sand Over } \\
\text { HardBottom }\end{array}$ & 36 & 376 & 0 & 0 & 0 & 412 & $91.3 \%$ \\
\hline & $\begin{array}{l}\text { Ridge + } \\
\text { SpurdCiroove }\end{array}$ & 47 & 76 & 377 & 10 & 0 & 510 & $73.9 \%$ \\
\hline & $\begin{array}{l}\text { Aggregate } \\
\text { Patch Reef }\end{array}$ & 0 & 0 & 0 & 47 & 5 & 52 & $90.4 \%$ \\
\hline & $\begin{array}{l}\text { Col. Pav. \& } \\
\text { Linear Reef }\end{array}$ & 0 & 0 & 0 & 7 & 439 & 446 & $98.4 \%$ \\
\hline & Total Columns & 1024 & 664 & 454 & 64 & 444 & 2650 & \\
\hline & $\begin{array}{l}\text { Producer } \\
\text { Accuracy }\end{array}$ & $91.9 \%$ & $56.6 \%$ & $83.0 \%$ & $73.4 \%$ & $98.9 \%$ & & $82.5 \%$ \\
\hline
\end{tabular}


habitat grouped with the relatively flat ridge habitat, the two otherwise disparate habitats having in common a low EcoSAVpredicted gorgonian abundance. The grouping in E1:E2 space of habitats with disparate substrata but similar gorgonian abundance is in agreement with the findings of Kloser et al. (2001), who reported that echo energies relate to a combination of seabed hardness and roughness attributes, including epibenthic biota.

\section{Selection of Acoustic Frequency}

The acoustic interpretation of RV was effectively the same at either 38 or $418 \mathrm{kHz}$. The El parameters of both frequencies ordered the seven arbitrarily-selected levels of RV in strictly ascending order and the E2 parameters of both frequencies ordered RV in strictly descending order, similar to what was observed by Hamilton, Mulhearn, and Poeckert (1999) for RoxAnn E1 and E2 values. The overall classification accuracies of the 38 and $418 \mathrm{kHz}$ signals were very similar; the question of which frequency performed best depended on seabed type. The $38 \mathrm{kHz}$ signal provided superior discrimination between the nearshore sand habitat and the adjacent sand over hardbottom habitat, indicating the lower frequency penetrated the surficial carbonate sediments sufficiently to allow the underlying hardbottom to act as a subsurface reflector, effectively amplifying E2. Schlagintweit (1993) also reported greater sediment penetration at $40 \mathrm{kHz}$ than at $208 \mathrm{kHz}$, and Greenstreet et al. (1997) speculated that a $38 \mathrm{kHz}$ echo could penetrate as far as $1 \mathrm{~m}$ into the seabed, depending on sediment density and water content.

The $38 \mathrm{kHz}$ signal was less adept than the $418 \mathrm{kHz}$ signal at discriminating between the intermediate-complexity reefal habitats and the sand habitats. For example, approximately $70 \%$ of the 38 $\mathrm{kHz}$ E1:E2 pairs collected over the ridge habitat fell within the sand E1:E2 box, compared to just $29.6 \%$ at $418 \mathrm{kHz}$ (Figure 7). Some acoustic confusion between habitats, regardless of frequency, was inevitable owing to the one acre minimum mapping unit used to delineate habitat classes, which resulted in some reefal habitats being constituted of a mixture of substrate classes. The greater acoustic confusion between the ridge and sand habitats at $38 \mathrm{kHz}$ was likely due to the longer wavelength of the $38 \mathrm{kHz}$ signal ( 4.04 $\mathrm{cm}$ versus $0.37 \mathrm{~cm}$ at $418 \mathrm{kHz}$ ) interacting less with the canopy of erect gorgonian colonies variably present in the ridge habitat but absent in the nearshore sand habitat. Similarly, the $418 \mathrm{kHz}$ signal better separated the colonized pavement and linear reef habitats from the other reefal habitats, due to a greater proportion of signal scattering contributing to El at $418 \mathrm{kHz}$ than at $38 \mathrm{kHz}$, but provided poor discrimination of the sand over hardbottom habitat from the sand and deep sand habitats. These observations support the opinion of Kloser et al. (2001) that echo energies relate to a combination of seabed hardness and roughness attributes, including epibenthic biota, and that the acoustic relationships are frequency dependent.

\section{CONCLUSIONS}

This study used spatially-coincident lidar bathymetry to quantitatively describe the acoustic interpretation of physical seabed characteristics over the extent of the survey area, instead of the common practice of using drop-video or scuba divers to collect validation data that may not adequately represent acoustic diversity. Inputs to the multi-echo classification method, E1 (tail of 1st echo) and E2 (complete 2nd echo), were critically evaluated for discriminatory capability. The individual acoustic energy parameters E1 and E2, like the lidar-derived reef-volume metric, differentiated between but did not unambiguously delineate lidar-delineated benthic habitat class. Multiple lines of evidence indicated that in the presence of abundant signal-scattering epibenthic biota (e.g., erect colonies of gorgonians), both acoustic parameters were informed primarily by seabed roughness. Increasing seabed roughness created more incoherent backscatter, increasing the value of El and decreasing the value of $\mathrm{E} 2$, as incoherent backscatter was less likely to complete the multi-path circuit. In the absence of abundant signal-scattering epibenthic biota, E1 and E2 were positively correlated. Although $\mathrm{E} 1$ and E2 were significantly correlated at both frequencies, there existed sufficient independence between the two acoustic parameters to successfully delineate benthic habitats using the E1:E2 bottom ratio seabed classification method. By all measures, the 38 and 418 $\mathrm{kHz}$ signals performed similarly in terms of detecting topographic complexity, substrate hardness, and the presence of epibenthic biota. The $418 \mathrm{kHz}$ signal was found optimal for discriminating the rougher seabeds from a joint contribution of topographic complexity and the presence of epibenthic biota, owing largely to the shorter wavelength of the high-frequency signal. The $38 \mathrm{kHz}$ signal was optimal for resolving the flat and comparatively featureless sand and sand over hardbottom habitats, owing to greater penetration of the lower-frequency signal. The comprehensive high-resolution lidar ground-truthing dataset was essential for these beginning steps towards uncovering the complicated relationships that exist between the acoustic energy parameters and the varied physical attributes of a coral reef environment.

\section{ACKNOWLEDGEMENTS}

We thank the various funding agencies that supported this work. This study was funded by DEP Agreement G0057 and NOAA Award NA160Z2440 to the Florida Marine Research Institute and National Coral Reef Institute. Special thanks to J. Bursczinsky and B. Moore at BioSonics Inc. for discussions and support, and to Kristi Foster for all her contributions to the acoustic survey. This is NCRI contribution \#101.

\section{LITERATURE CITED}

Anderson, J.T.; Gregory, R.S., and Collins, W.T., 2002. Acoustic classification of marine habitats in coastal Newfoundland. ICES Journal of Marine Science, 59(1), 156-157.

Brekhovskikh, L. and Lysanov, Y., 1982. Fundamentals of Ocean Acoustics; Springer Series in Electrophysics Volume 8. Berlin: Springer-Verlag, $250 \mathrm{p}$.

Burczynski, J., 1999. Bottom classification. Seattle, WA: BioSonics, Inc., 14p. URL: http:/www.biosonicsinc.com/doc_library/docs/bottom classification.pdf

Chivers, R.C.; Emerson, N., and Burns, D., 1990. New acoustic processing for underway surveying. The Hydrographic Journal, 56, 8-17.

Dommisse, M.; Urban, D.; Finney, B., and Hills, S., 2005. Potential depth biasing using the Biosonics VBT Seabed Classification Software. Marine Technology Society Journal, 39(2), 90-93.

Ellingsen, K.E.; Gray, J.S., and Bjornbom, E., 2002. Acoustic classification of seabed habitats using the QTC VIEW registered system. ICES Journal of Marine Science, 59(4), 825-835.

Foster-Smith, R.L. and Sotheran, A.R., 2003. Mapping marine benthic biotopes using acoustic ground discrimination systems. International Journal of Remote Sensing, 24(13), 2761-2784.

Freitas, R.; Rodrigues, A.M., and Quintino, V., 2003. Benthic biotopes remote sensing using acoustics. Journal of Experimental Marine Biology and Ecology. 285-286, 339-353. 
Ma, Z. and Redmond, R.L., 1995. Tau coefficients for accuracy assessment of classification of remote sensing data. Photogrammetric Engineering \& Remote Sensing, 61(4), 435-439.

Magorrian, B.H.; Service, M., and Clarke, W., 1995. An acoustic bottom classification survey of Strangford Lough, Northern Ireland. Journal of the Marine Biological Association of the UK, 75, 987-992.

McCauley, R.D. and Siwabessy, P.J.W., 2006. Practical guide to acoustic techniques for benthic habitat classification. Indooroopilly, Queensland, Australia: Cooperative Research Centre for Coastal Zone, Estuary and Waterway Management Technical Report 84, 39p.

McKinney, C.M. and Anderson, C.D., 1964. Measurements of backscattering of sound from the ocean bottom. Journal of the Acoustical Society of America, 36(1), 158-163.

Moyer, R.P.; Riegl, B.; Banks, K., and Dodge, R.E., 2005. Assessing the accuracy of acoustic seabed classification for mapping coral reef environments in South Florida (Broward County, USA). Revista de Biologia Tropical, 53(Suppl. 1), 175-184.

Orlowski, A., 1984. Application of multiple echo energy measurements for evaluation of sea bottom type. Oceanologia, 19, 61-78.

Riegl, B.M. and Purkis, S.J., 2005. Detection of shallow subtidal corals from IKONOS satellite and QTC View $(50,200 \mathrm{kHz})$ single-beam sonar data (Arabian Gulf; Dubai, UAE). Remote Sensing of Environment, 95, 96-114.

Riegl, B.M.; Halfar, J.; Purkis, S.J., and Godinez-Orta, L., 2007. Sedimentary facies of the Eastern Pacific's northernmost reef-like setting (Cabo Pulmo, Mexico). Marine Geology, 236, 61-77.

Rukavina, N.A., 1997. Substrate mapping in the Great Lakes nearshore zone with a RoxAnn acoustic sea-bed classifcation system. Proceedings of the Canadian Coastal Conference 1997 (Guelph, Ontario), pp. 338-349.

Sabol, B.; Melton, R.E.; Chamberlain, R.; Doering, P., and Haunert, K., 2002. Evaluation of a digital echo sounder for detection of submersed aquatic vegetation. Estuaries, 25(1), 133-141.

Schlagintweit, G.E.O., 1993. Real-time acoustic bottom classification: a field evaluation of RoxAnn. Oceans '93 (Victoria, British Columbia, IEEE), pp. 214-219.

von Szalay, P.G. and McConnaughey, R.A., 2002. The effect of slope and vessel speed on the performance of a single beam acoustic seabed classification system. Fisheries Research (Amsterdam), 56(1), 99-112.

Walker, B.K.; Riegl, B.M., and Dodge, R.E., 2008. Mapping coral reef habitats in southeast Florida using a combined technique approach. Journal of Coastal Research, 24(5), 1138-1150.

White, W.H.; Harborne, A.R.; Sotheran, I.S.; Walton, R., and Foster-Smith, R.L., 2003. Using an Acoustic Ground Discrimination System to map coral reef benthic classes. International Journal of Remote Sensing, 24(13), 2641-2660.

Wilding, T.A.; Sayer, M.D., and Provost, P.G., 2003. Factors affecting the performance of the acoustic ground discrimination system RoxAnn. ICES Journal of Marine Science, 60(6), 1373-1380. 